The following nine persons have been newly appointed as members of the Editorial Board of Analytical Sciences. The biographies of the current members are included in the June issues of the journal. Profs. Akira Harata, Takeshi Hasegawa, Yasuyuki Ishida, Yutaka Itabashi, Fumio Mizutani, Masaharu Nakayama, Yoshiki Sohrin, and Shigeo Tanuma have retired from the Editorial Board. As of March 21st, Prof. Koji Suzuki at Keio University is serving as the Editor-in-Chief. The former Editor, Prof. Totaro Imasaka, has retired from the Editorial Board.

\title{
ANALYTICAL SCIENCES EDITORIAL BOARD MEMBERS - BIOGRAPHIES
}

\section{Editor}

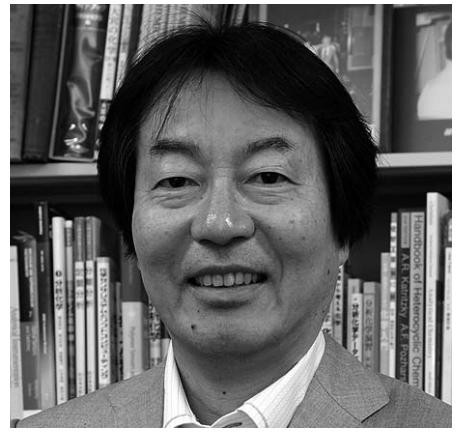

Koji SUZUKI, Professor of Department of Applied Chemistry, Faculty of Science and Technology, Keio University, was born in 1954 in Tokyo. He received Bachelor (1977), Master (1979) and Ph. D. (1982) degrees of Engineering from Keio University. He became a faculty member as a Research Associate in 1982, Assistant Professor in 1998, Associate Professor in 1993, and full Professor in 1998. From 1990 - 1992, he was a Guest Professor at the Swiss Federal Institute of Technology (ETH), Zurich. He is the Vice President of JSAC for 2011 2013. His research focuses on chemical and biochemical sensors based on functional molecule creation. He is also interested in seeing, listening to, or eating what is impressing. His motto is "do my best".

Sei FUKUSHIMA, Chief Researcher of Advanced Surface Chemical Analysis Group, Nano Characterization Unit, Advanced Key Technology Division, National Institute for Materials Science, was born in 1957 in Tottori Prefecture. He received Bachelor (1981), Master (1983) and $\mathrm{Ph}$. D. (1986) degrees of Engineering from University of Tokyo. He served as a Research Associate (1986 - 1990) at University of Tokyo, then a vice-senior researcher (1990 - 1994) at Fuji Xerox Co., Ltd., and has been as the present position since 1994. His main work is the investigation and development of chemical state analysis using atomic inner-shell phenomena, such as X-ray emission or X-ray photo-emission spectroscopy, aided by linear data-processing techniques. His current research interest is the investigation of spectral changes of XPS, Auger spectra and characteristic X-ray spectra by means of the cluster calculations. He enjoys dog sports (Frisbee dog) and seeking traces of forest or mining railways.

Associate Editor

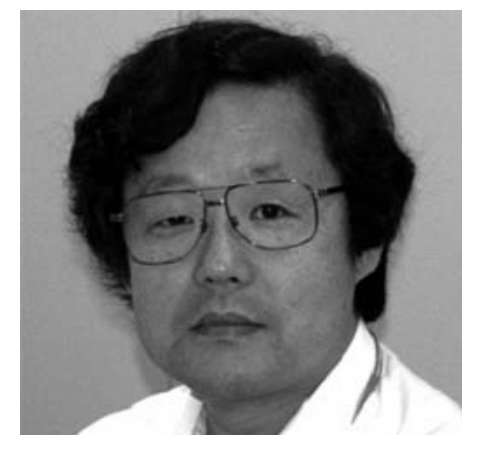

Associate Editor

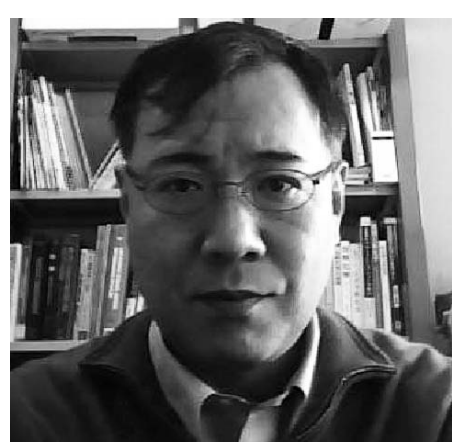

Hajime KatANO, Professor of Department of Bioscience, Fukui Prefectural University, was born in 1965 in Nagoya. He received Bachelor (1989), Master (1991), and Doctor (1994) degrees from Kobe University. He served as Research Associate (1994 - 1997), Lecturer (1997 2005), and Associate Professor (2005 - 2011), and was promoted to Professor at Fukui Prefectural University. His research interests are electroanalytical chemistry, including liquid-liquid interface electrochemistry and the material chemistry of performance chemicals including polymer additives.

Koji NAKano, Associate Professor of Department of Applied Chemistry, Faculty of Engineering, Kyushu University, was born in 1960 in Fukushima Prefecture. He received Bachelor (1983) and Master (1985) degrees from Tohoku University. In 1985 he was appointed to Research Associate at Faculty of Engineering, Kyushu University, and was then promoted to Associate Professor at College of General Education, Kyushu University in 1992. In 1994 with personnel relocation he moved to the Faculty of Engineering and since then until today, he has been on this faculty. During this period, he received a Doctor degree from Kyushu University (1993) and stayed at the laboratory of Prof. Edmond F. Bowden, Department of Chemistry, North Carolina State University as a visiting research scholar, 1995 - 1996. Currently, his scientific interest is focused on DNA nanobio-technology with a central focus on single-molecule measurements and molecular-chemical device developments.

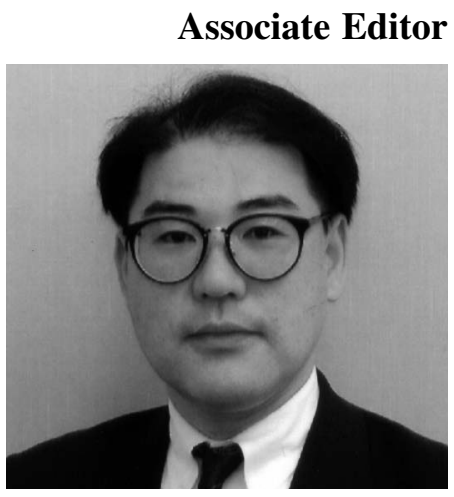




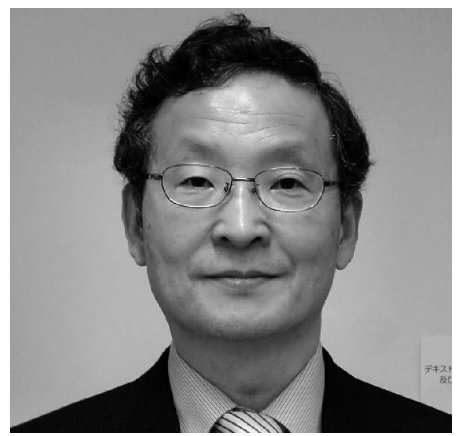

Associate Editor

Hiroyuki NISHI, Professor of Department of Pharmaceutical Chemistry, Faculty of Pharmacy, Yasuda Women's University, was born in 1958 in Hiroshima. He received Bachelor (1980) and Master (1982) degrees of Engineering from Kyoto University. After graduation, he immediately entered Tanabe Seiyaku Co., Ltd., as a researcher (1982). He then became chief researcher (1999 - 2004), section manager (2004 - 2006), and department manager (2006 - 2008). In 2008, he moved to his current position. During his researcher period, he received a Doctor (1991) degree of Pharmaceutical Sciences from Kyoto University. His current interest is the development of highly sensitive, selective separation methods employing UHPLC and capillary electrophresis. He likes visiting Kyoto and Nara (ancient cities).

Munetaka OYAMA, Associate Professor of Department of Materials Chemistry, Graduate School of Engineering, Kyoto University, was born in 1963 in Fukuoka. He received Bachelor (1986), Master (1988) and Doctor (1991) degrees of Science from Kyoto University. After being a research fellow of the Japan Society for the Promotion of Science (1990 - 1991), he joined Nagoya University as Research Associate (1991). In 1994, he moved to the present department, and was promoted to Associate Professor in 1999. After that, he moved to International Innovation Center, Kyoto University in 2001, but returned to the present position in 2007 . He was an academic visitor of Oxford University, UK from 1997 to 1998. His current research interests include the development of electroanalytical methods using nanomaterials.
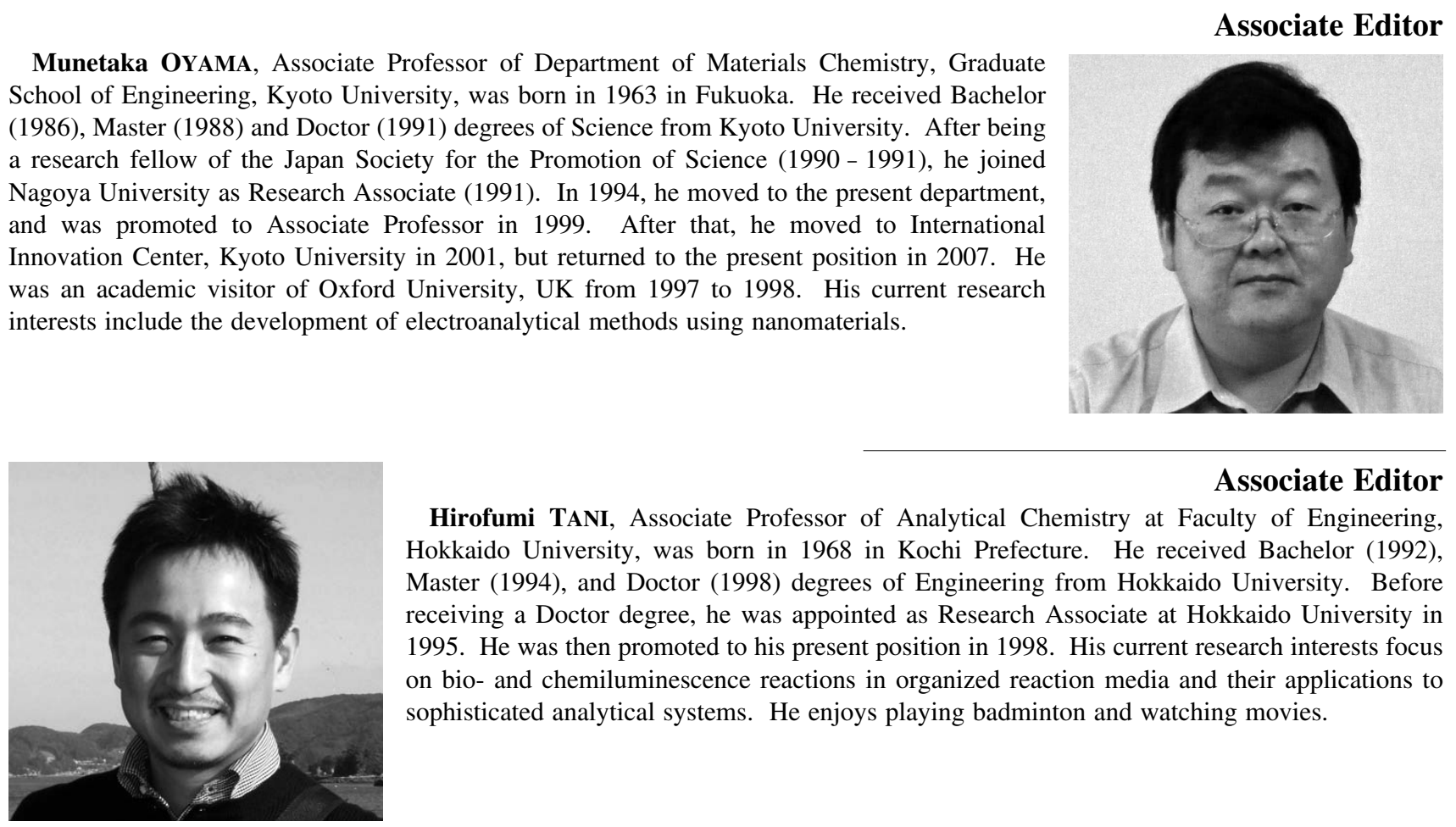

Associate Editor

Hirofumi TANI, Associate Professor of Analytical Chemistry at Faculty of Engineering, Hokkaido University, was born in 1968 in Kochi Prefecture. He received Bachelor (1992), Master (1994), and Doctor (1998) degrees of Engineering from Hokkaido University. Before receiving a Doctor degree, he was appointed as Research Associate at Hokkaido University in 1995. He was then promoted to his present position in 1998. His current research interests focus on bio- and chemiluminescence reactions in organized reaction media and their applications to sophisticated analytical systems. He enjoys playing badminton and watching movies.

Satoshi TSUKaHara, Professor of Analytical Chemisty, Department of Chemistry, Graduate School of Sciences, Osaka University, was born in 1964 in Ibaraki Prefecture. He received Bachelor (1986), Master (1988), and Doctor (1993) degrees of Science from Tohoku University. He served as a Research Associate (1989 - 1995, 1995 - 2003) at Tohoku and Osaka Universities, and then Associate Professor $(2003$ - 2011) at Hiroshima University. He was promoted to the present position in 2011. He received the Japan Society for Analytical Chemistry Award for Younger Researchers in 1998. His current research interest is the development of new microspectroscopic and ultrasensitive methods for reactions and phenomena at liquid/liquid interfaces.
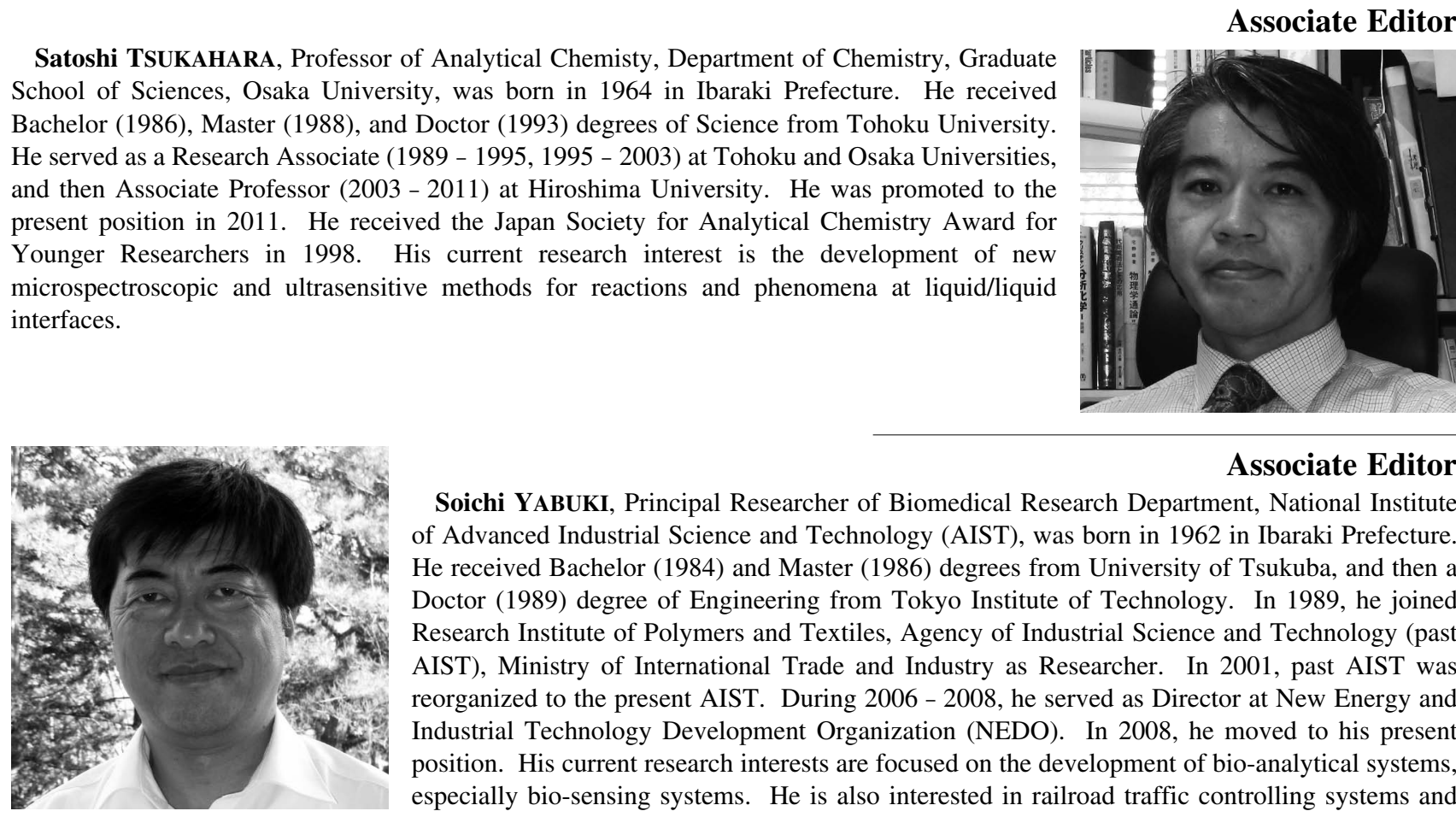

Associate Editor

Soichi YABUKI, Principal Researcher of Biomedical Research Department, National Institute of Advanced Industrial Science and Technology (AIST), was born in 1962 in Ibaraki Prefecture. He received Bachelor (1984) and Master (1986) degrees from University of Tsukuba, and then a Doctor (1989) degree of Engineering from Tokyo Institute of Technology. In 1989, he joined Research Institute of Polymers and Textiles, Agency of Industrial Science and Technology (past AIST), Ministry of International Trade and Industry as Researcher. In 2001, past AIST was reorganized to the present AIST. During 2006 - 2008, he served as Director at New Energy and Industrial Technology Development Organization (NEDO). In 2008, he moved to his present position. His current research interests are focused on the development of bio-analytical systems, especially bio-sensing systems. He is also interested in railroad traffic controlling systems and enjoys travelling by train. 